\title{
Ectopic Liver Tissue on the Gallbladder
}

\author{
(D) Cemil YÜKSEL ${ }^{1}$, ib Yunus DÖNDER ${ }^{1}$, (D) Nihal Deniz BULUT YÜKSEL², id Uğur IZOL33
}

'Kilis State Hospital, Clinic of General Surgery, Kilis, Turkey

${ }^{2}$ Kilis State Hospital, Clinic of Anesthesiology and Reanimation, Kilis, Turkey

${ }^{3}$ Kilis State Hospital, Pathology Laboratory, Kilis, Turkey

\begin{abstract}
Ectopic liver tissue is a rare developmental abnormality and is thought to be caused by aberrant migration in the embryological development of the liver. A 34-year-old female patient underwent laparoscopic cholecystectomy and ectopic liver tissue was found on the gallbaldder. Ectopic liver tissue was removed during cholecystectomy. Pathology was reported as normal liver tissue with the gallbladder tissue. Ectopic liver tissue is incidentally detected with no preoperative diagnosis. Ectopic liver tissue should be removed due to malignancy potential.
\end{abstract}

Keywords: Laparoscopy, gallbladder, ectopic liver tissue

\section{Introduction}

Ectopic liver is a rare developmental abnormality and its incidence is $0.24 \%-0.48 \%$ (1). The first case was published in 1922 . Ectopic liver is thought to develop due to aberrant migration occurred during embryological development (2). Although there are many different locations such as hepatic ligaments, falciform, omentum, diaphragm where it can locate; most oftenly it is located on the gallbladder (3). It can not be diagnosed by radiological imaging methodsand is usually seen during the operation. Although we have much knowledge about the ectopic liver the associated pathologies, treatment approaches, and complications should be known. Ectopic liver has been shown to have potential for hepatocellular cancer development (4). For this reason, removal of the ectopic liver is necessary. We present a patient in whom an ectopic liver on the gallbladder was detected during laparoscopic cholecystectomy performed due to cholelithiasis.

\section{Case Report}

A 34-year-old female patient had abdominal pain that was intermittent for about 1 year. It was associated with meals and sometimes was accompanied by nausea and vomiting. The patient had no comorbidities and physical examination showed minimal sensitivity on the right upper side and there was no defense or rebound. The patient did not use any drug. There was no significant feature in family history. In the preoperative laboratory tests; alanine aminotransferase: $49 \mathrm{U} / \mathrm{L}$, aspartate aminotransferase: $27 \mathrm{U} / \mathrm{L}$, alkaline phosphatase: $134 \mathrm{U} / \mathrm{L}$, total bilirubin: $1 \mathrm{mg} / \mathrm{dL}$, direct bilirubin: $0.5 \mathrm{mg} / \mathrm{dL}$, white blood cells: $9.58^{*} 10^{3}$, hemoglobin: 12.7 . There was no pathology in the chest X-ray. Preoperative hepatobiliary ultrasonography showed millimetric stones in the gallbladder and the wall thickness of the gallbladder was shown to be increased. The patient was evaluated as ASA1 by the anesthetistand the patient was operated. During laparoscopic cholecystectomy, on the medial side of the free face of the gallbladder fundus, a liver-like brown tissue was observed that was not associated with the liver. It was totally removed with the gallbladder (Figure 1). The patient was discharged on the first postoperative day without any complications. The patient did not have any complaints at follow ups. Chronic cholecystitis, cholelithiasis and ectopic liver tissue of $1.7 \mathrm{~cm}$ in diameter adhered to the gallbladder and microscopically; ectopic liver tissue with normal liver histology with bile ducts were reported in the pathology report (Figures 2 and 3). Written informed consent was obtained from patient. 


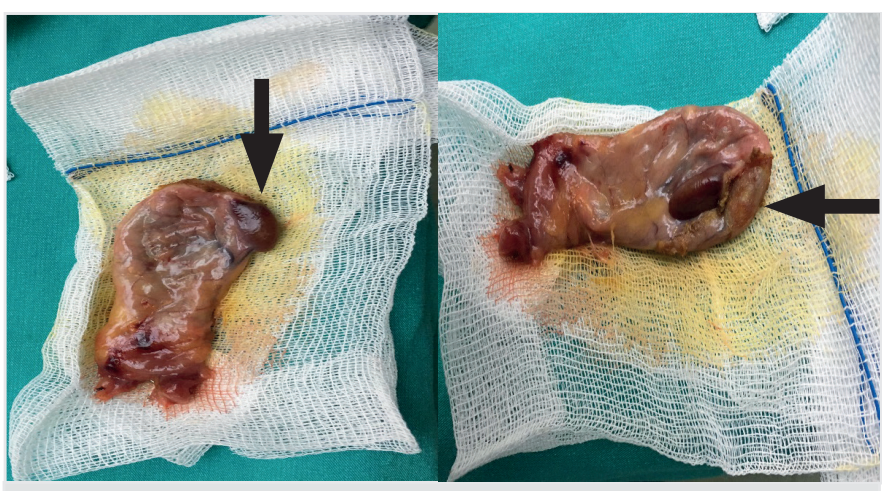

Figure 1. Macroscopic view of ectopic liver tissue of $1.7 \mathrm{~cm}$ in diameter marked with arrow on the gallbladder

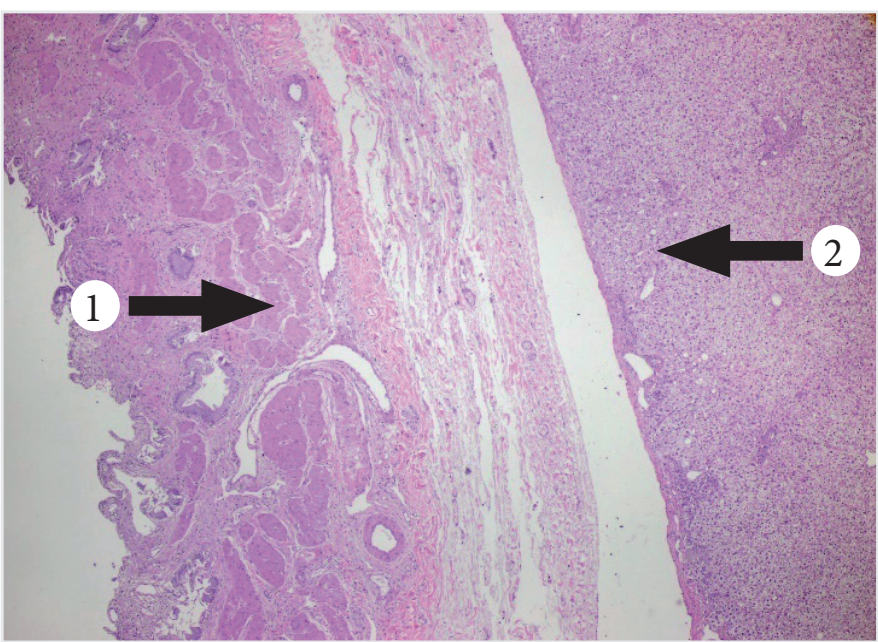

Figure 2. Microscopic view of the gallbladder and ectopic liver tissues (gallbladder tissue is shown by arrow 1, normal ectopic liver tissue is shown by arrow 2)

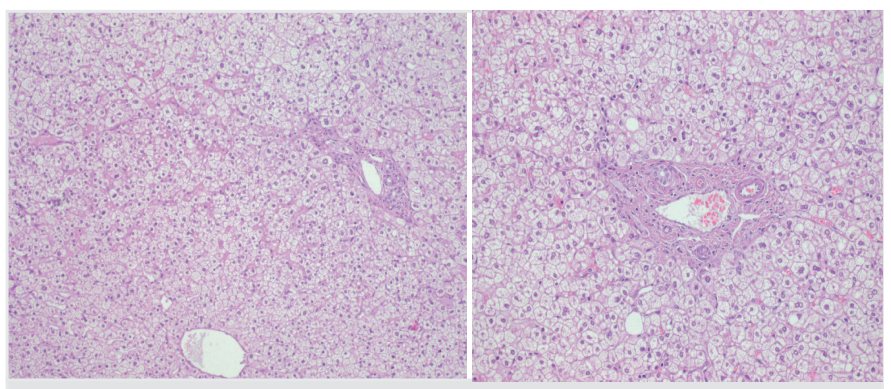

Figure 3. Histopathologic view of ectopic liver tissue

\section{Discussion}

The ectopic liver can be found in the abdomen or in the thorax, but most commonly on the gallbladder. The incidence is between $0.24 \%$ and $0.48 \%$ (1). Hepatobiliary system originates from foregut at the $4^{\text {th }}$ week of embryological development. Development of ectopic liver is thought to be caused by aberrant migration during the embryological development of the liver (2). Ectopic liver is frequently encountered incidentally during surgery (5). Patients often do not have symptoms. Symptoms may be due to torsion, necrosis, compression, or malignant transformation. However, it may cause cholelithiasis and cholecystitis (6). Ectopic liver may rarely be associated with some abnormalities. Ectopic liver can be seen rarely with cardiac abnormalities, biliary atresia, omphalocele and biliary duct cysts (7).

Ectopic liver tissue is generally not diagnosed, preoperatively. By ultrasound imaging, ectopic liver on the gallbladder can be seen and can be diagnosed with biopsy but biopsy should notbe done due to risk of bleeding and malignant spread.

In general, the pathology is reported as normal liver histology. Sometimes bile or portal vascular system may not develop. Although not fully proven, several publications have shown that ectopic liver increases the risk of hepatocellular cancer. This is thought to be caused by insufficient bile drainage and low arterial feeding (8).

Ectopic liver tissue should be removed because of the risk of malignancy. Ectopic liver tissue on the gallbladder should be resected together with the gallbladder. The vascular component of ectopic liver tissue is not seen, oftenly. If the liver has a vascular component, it is necessary to dissect the vascular component before separating the gallbladder from the liver bed. In this way, unwanted bleeding can be avoided.

As a result, ectopic liver is very rare and it is incidentally seen during surgery. It is most commonly found on the gallbladder. Ectopic liver is removed when it is seen because of risk of hemorrhage, pressure, rupture, necrosis and hepatic cancer.

\section{Ethics}

Informed Consent: Written informed consent was obtained from patient.

Peer-review: Externally peer-reviewed.

\section{Authorship Contributions}

Surgical and Medical Practices: C.Y., Y.D., Concept: N.D.B.Y., U.I.., Design: N.D.B.Y., C.Y., Data Collection or Processing: Y.D., U.İ., Analysis or Interpretation: U.İ., Literature Search: C.Y., Writing: Y.D.

Conflict of Interest: No conflict of interest was declared by the authors.

Financial Disclosure: The authors declared that this study received no financial support.

\section{References}

1. Martinez CA, de Resende HC Jr, Rodrigues MR, Sato DT, Brunialti CV, Palma RT. Gallbladder-associated ectopic liver: A rare finding during a laparoscopic cholecystectomy. Int J Surg Case Rep 2013;4:312-5.

2. Zwaenepoel T, Dierickx D, Laleman W, Sciot R. Ectopic liver tissue in two distinct anatomical regions: a case report. Acta Gastroenterol Belg 2014;77:68-70.

3. Vaideeswar P, Yewatkar D, Nanavati R, Bhuiyan P. Ectopic liver tissue in umbilical cord. J Postgrad Med 2011;57:22930. 
4. Arakawa M, Kimura Y, Sakata K, Kubo Y, Fukushima T, Okuda K. Propensity of ectopic liver to hepatocarcinogenesis: case reports and a review of the literature. Hepatology 1999;29:57-61.

5. Griniatsos J, Riaz AA, Isla AM. Two cases of ectopic liver attached to the gallbladder wall. HPB (Oxford) 2002;4:191-4.

6. Iber T, Rintala R. Intrapulmonary ectopic liver. J Pediatr Surg 1999;34:1425-6.
7. Watanabe M, Matsura T, Takatori Y, Ueki K, Kobatake T, Hidaka M, et al. Five cases of ectopic liver and a case of accessory lobe of the liver. Endoscopy 1989;21:39-42.

8. Leone N, De Paolis P, Carrera M, Carucci P, Musso A, David E, et al. Ectopic liver and hepatocarcinogenesis: report of three cases with four years' follow-up. Eur J Gastroenterol Hepatol 2004;16:731-5. 